\title{
Characterization of mammary stromal remodeling during the dry period
}

\author{
L. D. De Vries, H. Dover, T. Casey, M. J. VandeHaar, and K. Plaut ${ }^{1}$ \\ Department of Animal Science, Michigan State University, East Lansing 48824-1225
}

\begin{abstract}
During the dry period between successive lactations, the mammary gland of dairy cows undergoes extensive remodeling that is marked by phases of involution and mammogenesis. Changes in the mammary epithelium during the dry period have been well characterized; however, few studies have examined the changes that occur in stromal tissue. The objective of this study was to characterize changes that occur in mammary stroma during the dry period. Mammary biopsies were taken from 9 multigravid Holstein cows in late lactation, at 1 wk after dry-off, 3 wk before expected calving date, and 1 wk before expected calving date. Tissue was fixed in formalin, embedded in paraffin, and cut into $5-\mu \mathrm{m}$ sections. Sections were stained with hematoxylin and eosin or with immunohistochemistry for expression of smooth muscle $\alpha$ actin (SMA), fibronectin, stromelysin-1 (MMP-3), transforming growth factor- $\beta 1$ (TGF- $\beta 1$ ), and TGF- $\beta$ receptor 2 (TGF- $\beta$ R2). Images of tissues were captured with light microscopy, and imaging software was used to measure intralobular stromal area, number of activated fibroblasts, as identified by expression of SMA, and percentage of intralobular stromal area expressing fibronectin, MMP3, TGF- $\beta 1$, and TGF- $\beta$ R2. Analyses of variance were conducted and statistical differences were based on the least squares means of biopsy stage. Number of activated fibroblasts was greater at 1 wk dry than at 1 wk before calving (2,720 vs. 1,800 cells $\left./ \mathrm{mm}^{2}\right)$, percentage intralobular stromal area was greater at $1 \mathrm{wk}$ dry $(32 \%)$ and $3 \mathrm{wk}$ before calving (37\%) than at 1 wk before calving (25\%), and TGF- $\beta 1$ expression decreased $15 \%$ from late lactation to the dry period. The percentages of stromal area expressing fibronectin, MMP-3, and TGF- $\beta R 2$ and the percentage of myofibroblasts were not different across biopsy stages. These results support the concept that stromal expression of transforming growth factor- $\beta 1$ and fibroblast proliferation may be important for remodeling during the dry period.
\end{abstract}

Received September 22, 2009.

Accepted February 9, 2010.

${ }^{1}$ Corresponding author: kplaut@anr.msu.edu
Key words: mammary, remodeling, dry period, stroma

\section{INTRODUCTION}

A dry period of 45 to $60 \mathrm{~d}$ between lactations is generally recommended to prevent milk production losses in a subsequent lactation (Klein and Woodward, 1943; Swanson, 1965; Coppock et al., 1974). Reducing the length of the dry period without loss of milk yield would improve efficiency of dairy production by reducing the number of unproductive days in the lifetime of a cow. However, the effects on postpartum health, reproduction, and milk production have provided conflicting evidence for the argument to shorten the dry period (Kuhn et al., 2006; de Feu et al., 2009; Watters et al., 2009). A better understanding of the mechanisms of mammary changes during the dry period may provide the evidence needed to develop a dry period strategy based on the biological needs of the cow.

Milk production is likely a function of the number and secretory activity of epithelial cells in ruminants (Knight and Peaker, 1984); thus, many investigators have focused on the role of the epithelial cells in the mammary gland during the dry period. Other cell types and tissues, however, may play a critical role during remodeling of the mammary gland and should not be overlooked. The mammary epithelium is closely linked to the stroma through the basement membrane extracellular matrix (ECM). There is extensive evidence that stromal tissue regulates and coordinates changes in the epithelium during mammary development in the mouse (Kratochwil, 1969; Silberstein et al., 1992; Joseph et al., 1999). An understanding of changes in the stromal tissue surrounding the epithelium during the dry period of dairy cows may provide insight into new strategies to manage or shorten the dry period without compromising milk production.

Most of the literature available on mammary involution is based on studies that examine involution in rodents that are not pregnant during this stage of mammary remodeling. In light of these physiological differences, mammary remodeling in the dairy cow during the dry period cannot be directly compared with rodent models of involution. The typical dry period in 
a dairy cow is characterized by 2 main phases: active involution after cessation of milk removal followed by a period of redevelopment before the next lactation (Hurley, 1989). During the involution phase, stromal area increases and parenchymal area decreases (Sordillo and Nickerson, 1988; Capuco et al., 1997), which is accompanied by an increase in the rate of epithelial cell apoptosis from $2.4 \%$ in late lactation to $4.8 \%$ after dryoff (Wilde et al., 1997). After approximately 3 wk of involution, the next stage of the dry period begins. This mammogenic period is characterized by redevelopment of the gland beginning 3 to 4 wk before parturition. During this time, the luminal area in the mammary tissue increases and the stromal compartment decreases through 1 wk prepartum (Sordillo and Nickerson, 1988; Hurley, 1989; Capuco et al., 1997).

Stromal remodeling is partly regulated by proteases that degrade ECM proteins. The expression levels of mRNA for several proteinases, including matrixmetalloproteinase (MMP)-2 and MMP-14, and their inhibitors, increase during involution of the bovine mammary gland (Rabot et al., 2007). In mice, mRNA expression and activity of MMP-3, a broad-specificity protease synthesized by stromal fibroblasts, are induced at the onset of forced involution (Talhouk et al., 1992). Matrix-metalloproteinase-3, also known as stromelysin, has been implicated in induction of mammary epithelial apoptosis through degradation of the basement membrane that is needed for alveolar cell survival (Sympson et al., 1994). Expression of MMP-3 mRNA is greatest during times of active remodeling of the mouse mammary gland (Sorrell et al., 2005), and MMP-3 degrades intralobular stromal proteins, suggesting that it likely mediates mammary remodeling and ductal morphogenesis and elongation (Simian et al., 2001). Although the effects of MMP-3 are well characterized in mice, the presence and activity of MMP-3 in mammary tissue has not been studied for dairy cattle.

Transforming growth factor- $\beta 1$ (TGF- $\beta 1$ ), a cytokine that acts through its type I and type II receptors (TGF $\boldsymbol{\beta R 2} 2$ ), is expressed in the bovine mammary gland during times of active remodeling and mediates stromal cell proliferation and epithelial cell apoptosis (for review, see Plaut et al., 2003). The greatest expression of TGF- $\beta 1$ in the bovine mammary gland was detected during mammogenesis in prepubertal heifers and during early involution (Plath et al., 1997). Interestingly, exogenous TGF- $\beta 1$ treatment of prepubertal bovine mammary glands increased stromal fibronectin expression and stromal cell proliferation from 1.8 to $3.5 \%$ (Musters et al., 2004). Transforming growth factor- $\beta 1$ induces epithelial to mesenchymal trans-differentiation in normal mammary epithelial cell lines (Yao et al., 2004; Casey et al., 2007) and activation of fibroblasts into myofibroblasts both in primary mammary cell culture (Yao et al., 2004; Casey et al., 2007) and in vivo (Roberts et al., 1986). Myofibroblasts are activated fibroblasts that express the contractile protein smooth muscle $\alpha$-actin (SMA) and are characterized by enhanced endoplasmic reticuli and an increased capacity to synthesize ECM proteins and proteases (Greiling and Clark, 1997; Phan, 2008).

Much of the research pertaining to the mammary gland of dry dairy cattle has focused on epithelial cells or gene expression of combined stromal and parenchymal tissue and has not examined the potential role of the stroma. Extensive studies done with mice have documented the inductive nature of mammary stroma on epithelial cell development and differentiation (Levine and Stockdale, 1985; Silberstein et al., 1992). These studies characterized the critical role of the stroma in directing the behavior of epithelial cells and indicated the need to define the role of stroma in bovine mammary development to gain a better understanding of factors that may affect milk production.

The objective of this study was to characterize mammary stromal changes during the dry period in the dairy cow. The relative numbers of fibroblasts and myofibroblasts and the expression of fibronectin, MMP-3, TGF- $\beta 1$, and TGF- $\beta$ R2 in stroma were assessed at 4 stages from late lactation through the dry period. We observed changes in the area and composition of the stroma and in expression of stromal TGF- $\beta 1$ during the dry period.

\section{MATERIALS AND METHODS}

\section{Animals}

All animal handling and surgical procedures were performed humanely under the approval of the Michigan State University Institutional Animal Care and Use Committee. Nine multigravid Holstein cows (5 primiparous, 4 multiparous) impregnated between 90 and 105 DIM from the Michigan State University Dairy Cattle Teaching and Research Center were used to obtain mammary biopsies. Cows were dried off at $310 \pm$ 12 DIM and had an average dry period length of $55 \pm$ $5 \mathrm{~d}$. A summary of lactation, gestation, and dry period lengths is presented in Table 1.

\section{Experimental Design}

Cows were biopsied from separate quarters of the mammary gland at 4 stages during late lactation and the dry period. Each quarter was sampled only once so that a previous biopsy would not influence subsequent biopsies. The quarters were randomly assigned to be bi- 
Table 1. Summary of cow information $(\mathrm{n}=9$ cows $)$

\begin{tabular}{|c|c|c|c|c|}
\hline Item & Mean & $\mathrm{SD}$ & Minimum & Maximum \\
\hline Milk production at dry-off $(\mathrm{kg} / \mathrm{d})$ & 19.4 & 7.7 & 8.3 & 36.9 \\
\hline Total DIM at dry-off (d) & 310 & 12 & 282 & 324 \\
\hline Total dry period length (d) & 55 & 5 & 49 & 66 \\
\hline \multicolumn{5}{|l|}{ Late lactation } \\
\hline Milk production (kg/d) & 26.6 & 11.0 & 11.9 & 42.7 \\
\hline DIM & 277 & 10 & 255 & 289 \\
\hline Days in gestation & 190 & 3 & 182 & 193 \\
\hline \multicolumn{5}{|l|}{1 wk dry } \\
\hline Days dry & 7 & 0 & 7 & 7 \\
\hline Days in gestation & 230 & 6 & 216 & 235 \\
\hline \multicolumn{5}{|l|}{3 wk before calving } \\
\hline Days prepartum & 19 & 2 & 15 & 22 \\
\hline Days dry & 36 & 6 & 30 & 49 \\
\hline Days in gestation & 259 & 1 & 258 & 260 \\
\hline \multicolumn{5}{|l|}{1 wk before calving } \\
\hline Days prepartum & 5 & 2 & 3 & 8 \\
\hline Days dry & 50 & 7 & 46 & 63 \\
\hline Days in gestation & 272 & 2 & 269 & 276 \\
\hline
\end{tabular}

opsied at different stages starting in different seasons to average the potential seasonal variation that may have influenced mammary remodeling in the dry period. The first biopsy was obtained during late lactation (LL). The second biopsy was obtained 1 wk after dry-off $(\mathbf{1}$ WD) to correspond with the time of expected active involution. The third biopsy was obtained 3 wk before expected calving date (3 BEC), during expected mammogenesis, and the final biopsy was obtained 1 wk before expected calving date (1 BEC), during late mammogenesis or early lactogenesis.

\section{Biopsy Procedure}

Biopsies were obtained using the method described by Farr et al. (1996) with several modifications. In brief, cows were restrained and sedated with an intramuscular injection of xylazine hydrochloride $(35-45 \mu \mathrm{g} /$ $\mathrm{kg}$ of BW; AnaSed, Lloyd Laboratories, Shenandoah, IA). The biopsy site was shaved and then washed with iodine, surgical iodine scrub, and $70 \%$ ethanol. Topical lidocaine gel was applied to the biopsy site to improve cow comfort before a 3 -mL s.c. lidocaine injection was administered. Approximately $1 \mathrm{~g}$ of tissue was collected using a stainless steel, retractable biopsy tool (AgResearch, Hamilton, New Zealand). Sterile absorbable gelatin sponge (Gelfoam, Pfizer, New York, NY) was placed in the biopsy site when excessive bleeding occurred. The incision area was closed with surgical staples and Autoclips (Becton, Dickinson and Company, Franklin Lakes, NJ). A teat cannula was inserted immediately after the first biopsy (LL) and the fourth biopsy (1 BEC) and removed after cessation of drainage to minimize the formation of intramammary clots and improve cow comfort. Biopsied lactating quarters were milked by hand and machine twice daily until the milk was free of visible blood to prevent blood clots. After the fourth biopsy, dry cows were milked twice daily beginning on the day of the biopsy procedure. Overall milk production in the lactation following the biopsies was not affected by the biopsy procedure (Dover et al., 2008).

\section{Tissue Processing}

Biopsied tissue was immediately placed in cold medium (Waymouth's Medium 752/1, Sigma, St Louis, MO) sterilized using a $0.1-\mu \mathrm{m}$ filter. The medium was supplemented with $50 \mu \mathrm{g}$ of gentamicin (Invitrogen, Carlsbad, CA) and $100 \mathrm{U}$ of penicillin and $100 \mu \mathrm{g}$ of streptomycin (Sigma) per mL. Biopsied tissue was rinsed in PBS containing $100 \mathrm{U}$ of penicillin and 100 $\mu \mathrm{g}$ of streptomycin (Sigma) and $1.5 \mu \mathrm{g}$ of amphotericin $\mathrm{B}$ (Invitrogen) per $\mathrm{mL}$, cut into $0.5 \mathrm{~cm}^{2}$ sections, and fixed overnight in buffered formalin. After $24 \mathrm{~h}$ of formalin fixation, tissue was transferred to $60 \%$ ethanol, embedded in paraffin, cut into 5 - $\mu \mathrm{m}$ tissue sections, and placed on silanized slides. One hematoxylin and eosin stained slide for each paraffin block was obtained for a general histological examination.

\section{Immunohistochemistry}

Immunohistochemistry was run in sets, with each set consisting of a slide for each of the 4 biopsies of a single cow, a positive control slide, and a negative control slide. A broad-spectrum streptavidin-peroxidase Histostain kit (Zymed Laboratories Inc., San Francisco, CA) was used according to the manufacturer's directions. Before immunohistochemistry, slides were incubated overnight 

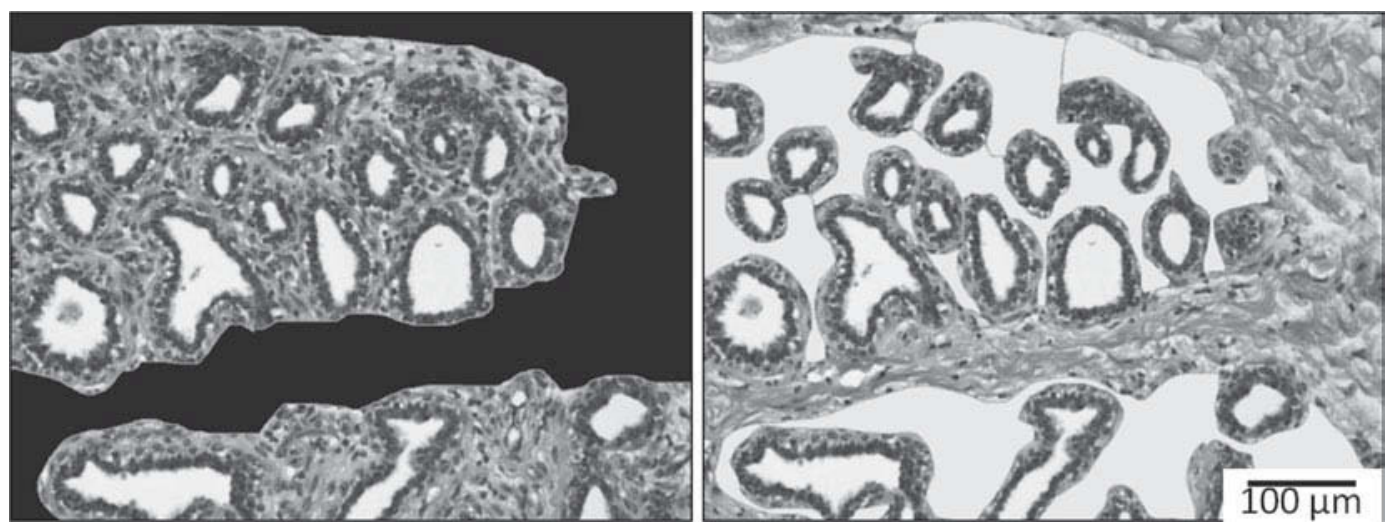

Figure 1. Example of intralobular stromal area measurement. Sample of intralobular and interlobular stromal area highlighted in hematoxylin and eosin stained images at 200× magnification. Left $=$ interlobular stromal highlighted black; right = intralobular stromal area highlighted white. Interlobular stromal area was not included in stromal area measurements.

at $60^{\circ} \mathrm{C}$, deparaffinized in xylene, rehydrated through a graded series of ethanol washes $(100,95,70$, and $60 \%$ ), and rinsed in PBS. Endogenous peroxidases were blocked for $15 \mathrm{~min}$ in $3 \%$ hydrogen peroxide in methanol. With the exception of anti-MMP-3, sodium citrate antigen retrieval was performed in a $100^{\circ} \mathrm{C}$ water bath for all antibodies (Jiao et al., 1999). Following antigen retrieval, sections were incubated for $10 \mathrm{~min}$ at room temperature in nonimmune blocking serum block (Histostain kit, Zymed). All sections were incubated with the primary antibody at room temperature.

Primary antibodies were selected for use based on how well they matched one or more of the following criteria: proven reactivity with bovine tissue, epitope sequence homology to bovine (determined with the Basic Local Alignment Search Tool 2.0, NCBI; http:// blast.ncbi.nlm.nih.gov/Blast.cgi), previous use in mammary tissue, or proven use in immunohistochemistry of paraffin-embedded tissue sections. The primary antibodies used were mouse monoclonal anti-smooth muscle $\alpha$-actin (1:10,000, 45 min; A2547, Sigma), mouse monoclonal anti-fibronectin $(50 \mu \mathrm{g} / \mathrm{mL}, 1 \mathrm{~h}$; MS-1351-R7, Lab Vision Products, Fremont, CA), rabbit polyclonal anti-TGF- $\beta 1(\mathrm{~V})$ (1:100, 1 h; SC-146, Santa Cruz Biotechnology Inc., Santa Cruz, CA), rabbit polyclonal anti-TGF- $\beta$ R2 C-16 (1:100, 1 h; SC-220, Santa Cruz Biotechnology Inc.), and mouse polyclonal anti-MMP-3 (1:200, 45 min; 3523R-100, Biovision Inc., Mountain View, CA). Sections were washed in PBS and incubated with a broad-spectrum secondary antibody conjugated with streptavidin-peroxidase (Histostain kit, Zymed Laboratories Inc.), followed by a PBS wash and 3-min incubation with $3^{\prime}, 3^{\prime}$-diaminobenzidine chromogen substrate. All slides were counterstained with hematoxylin, dehydrated in a graded series of alcohols, cleared in xylene, and mounted with Histomount (Zymed).

\section{Photomicrograph Analysis}

Stained slides were examined with a Nikon Eclipse 50i light microscope (Nikon Instruments Inc., Melville, NY). Five photomicrographs were taken per slide at $200 \times$ magnification, avoiding areas high in interlobular stroma or areas close to tissue section edges. Images were captured at a size of 2,560 by 960 pixels with 32-bit/pixel depth and saved in tagged image file format (TIFF) in Image Pro Plus 5.1 (Media Cybernetics, Bethesda, MD). Each image represented a tissue area of $0.29 \mathrm{~mm}^{2}$. Histological measurements were obtained using the freehand area-of-interest tool to measure the area or the manual tag tool for counting cells in Image Pro Plus. An example of the intralobular stromal area measurement is presented in Figure 1.

Protein expression levels for TGF- $\beta 1$, TGF- $\beta$ R2, fibronectin, and MMP-3 were determined by measuring the percentage of intralobular stroma area stained by immunohistochemistry. Stromal cells with phenotypic characteristics of fibroblasts (paler nuclei, and not associated with blood vessels or other structures) were considered fibroblasts. Fibroblasts expressing SMA were considered activated fibroblasts or myofibroblasts. These results are presented as a percentage of all fibroblast cells (fibroblasts and myofibroblasts) in the intralobular stroma, and as the number of cells per area of intralobular stroma $\left(\right.$ cells $\left./ \mathrm{mm}^{2}\right)$.

\section{Fibronectin, TGF- $\beta 1$, TGF- $\beta$ R2, and MMP-3 Expression}

To determine the stromal protein expression of fibronectin, TGF- $\beta 1$, TGF- $\beta$ R2, and MMP-3, positive (brown) staining was selected in the intralobular stromal area using the eyedropper tool in the Count/Size dialog of Image Pro Plus. Using the eyedropper tool, settings 
for positive $3^{\prime}, 3^{\prime}$-diaminobenzidine staining were saved and applied to all biopsy stages within a cow, including the positive and negative control slides run within each set. The stained area was expressed as a percentage of the total intralobular stromal area measured in each image. Samples of staining are presented in Figure 2.

\section{Statistical Analysis}

Analysis of variance of the data was conducted with the MIXED procedure in SAS v.9.1.3 software (SAS Institute Inc., Cary, NC) using the following model:

$$
\mathrm{Y}_{\mathrm{ij}}=\mu+\mathrm{C}_{\mathrm{i}}+\mathrm{B}_{\mathrm{j}}+\mathrm{e}_{\mathrm{ij}} \text {, }
$$

where $\mu=$ overall mean, $\mathrm{C}=$ random effect of cow $(\mathrm{i}=$ 1 to 9 cows), $B=$ fixed effect of biopsy stage $(\mathrm{j}=1$ to 4 stages), and $\mathrm{e}=$ residual error.

The effect of parity (primiparous or multiparous) and the interaction between cow and biopsy stage were evaluated but removed from the model when declared not significant $(P>0.1)$. Results were considered statistically significant at a probability of $\alpha<0.05$. Statistical differences were based on the least squares means of biopsy stage with the following comparisons: lactation (LL) versus dry period (1 WD, 3 BEC, 1 $\mathrm{BEC}$ ), involution (1 WD) versus late mammogenesis (1 BEC), and early mammogenesis (3 BEC) versus late mammogenesis (1 BEC). Although comparisons were preplanned, a Bonferroni adjustment was applied because comparisons were nonorthogonal. Results are presented as least squares means \pm standard error of the mean.

\section{RESULTS}

\section{Intralobular Stromal Area and Tissue Characteristics}

There was a significant effect of biopsy stage on the percentage intralobular stroma $(P=0.02)$. Intralobular stromal area was greater at $3 \mathrm{BEC}(37 \% \pm 4.7 ; P=$ $0.005)$ and tended to be greater at $1 \mathrm{WD}(32 \% \pm 4.7 ; P$ $=0.08)$ compared with 1 BEC $(25 \% \pm 4.7$; Figure 3$)$. Tissue from the LL biopsy stage was variable in structure and integrity. Parenchyma in LL showed evidence of both intact and collapsing alveoli, including alveoli with incomplete basement membranes. In contrast, parenchymal tissue morphology at other biopsy stages appeared more uniform throughout samples.

\section{Fibronectin Expression}

Fibronectin staining was present in all tissue sections at all biopsy stages (Figure 2). The interlobular stroma appeared to have more fibrous sheets and more intense fibronectin staining than the intralobular stroma. A distinct band of fibronectin staining was also observed within the basement membrane. The percentage intralobular stromal area expressing fibronectin was not different across biopsy stages (Figure 4).

\section{MMP-3 Expression}

Matrix-metalloproteinase-3 was also present in all tissue sections at all biopsy stages (Figure 2). We observed more intense, darker staining of MMP-3 on the apical side of alveolar epithelial cells and in the interlobular stroma. Although intensity was not quantified in this study, we observed that the intralobular stroma stained diffusely with less intensity for MMP-3 compared with the interlobular stroma and epithelium. The percentage intralobular stromal area expressing MMP-3 was not different across biopsy stages (Figure 4).

\section{TGF- $\beta 1$ and TGF- $\beta R 2$ Expression}

Transforming growth factor- $\beta 1$ and TGF- $\beta$ R2 were expressed in stromal and epithelial cells in tissue sections from all biopsy stages (Figure 2). We observed diffuse, light staining of TGF- $\beta 1$ and TGF- $\beta R 2$ in the intralobular stroma. The intralobular stromal expression of TGF- $\beta 1$ decreased $15 \%$ from LL to the dry period ( $1 \mathrm{WD}, 3 \mathrm{BEC}, 1 \mathrm{BEC} ; P=0.02)$. Expression of TGF- $\beta 1$ in the intralobular stroma was similar across biopsy stages. Percentage of the intralobular stroma expressing TGF- $\beta$ R2 protein was similar at all biopsy stages (Figure 4).

\section{Fibroblasts and Myofibroblasts}

As expected, myoepithelial cell expression of SMA appeared as a distinct ring, delineating the basement membrane around the alveoli in tissue sections from all biopsies (Figure 2). Smooth muscle $\alpha$-actin was also detected around blood vessels. Fibroblast-like stromal cells that expressed SMA were considered to be activated myofibroblasts. Although the percentage of myofibroblasts was similar across all biopsy stages, there may have been a biologically important increase in the percentage of myofibroblasts at $1 \mathrm{WD}$ compared with LL (18 to $22 \% ; P=0.11$; Table 2 ). There was no difference in the number of myofibroblasts per $\mathrm{mm}^{2}$ of intralobular stromal tissue. Biopsy stage tended to alter the number of fibroblasts $(P=0.10)$, with a decrease in number of fibroblasts from $1 \mathrm{WD}$ to 1 BEC $(2,720$ \pm 270 to $1,800 \pm 270$ cells $/ \mathrm{mm}^{2} ; P=0.02$; Figure 5 , Table 2). 
DE VRIES ET AL.

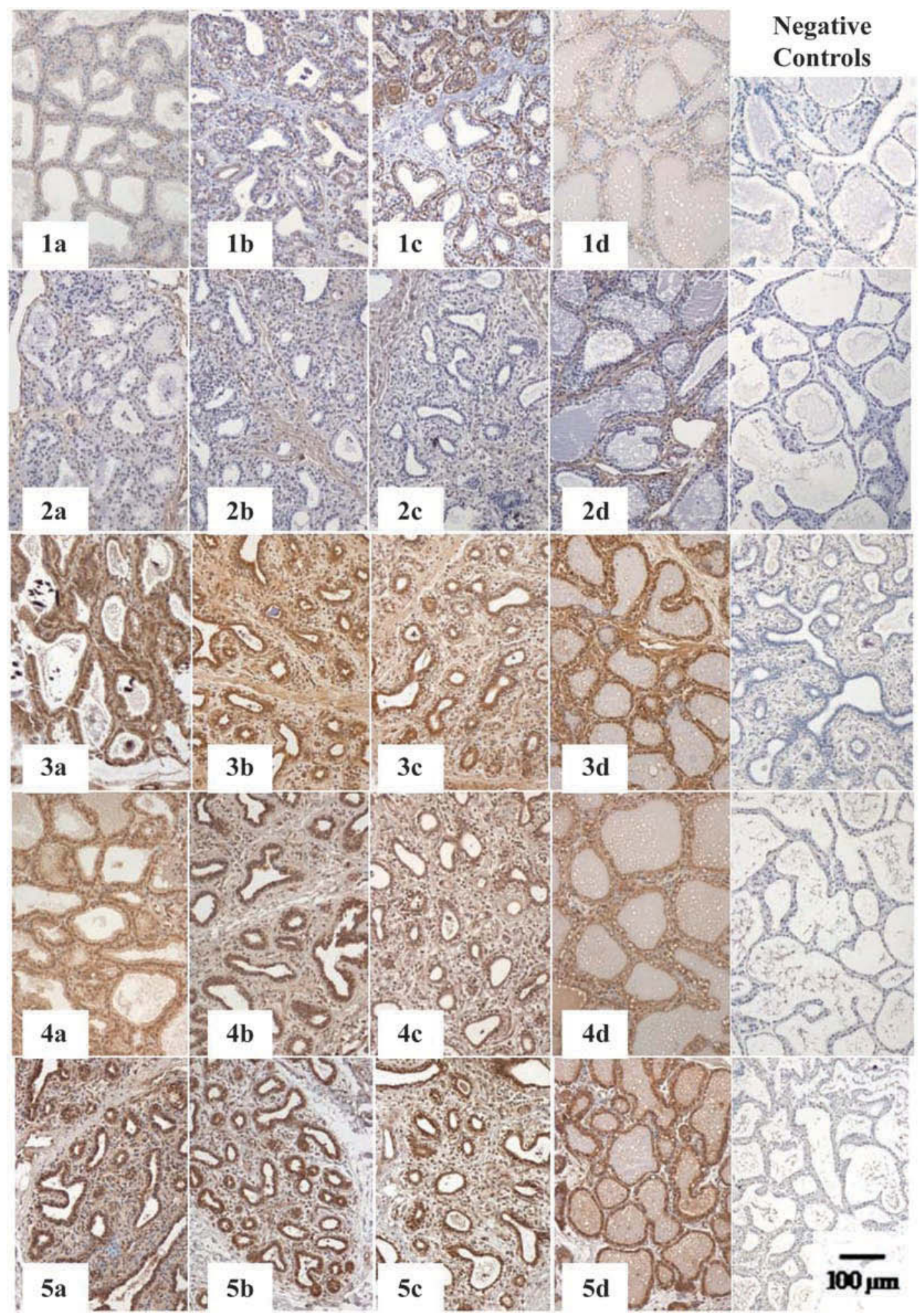

Figure 2. Immunohistochemical staining of stromal proteins. Each panel represents a different protein $(1=$ smooth muscle $\alpha$-actin; $2=$ fibronectin; $3=$ matrix-metalloproteinase- $3 ; 4=$ transforming growth factor- $\beta 1 ; 5=$ transforming growth factor- $\beta \mathrm{R} 2)$ and stage $(\mathrm{a}=$ late lactation; $\mathrm{b}=1 \mathrm{wk}$ dry; $\mathrm{c}=3 \mathrm{wk}$ before calving; $\mathrm{d}=1 \mathrm{wk}$ before calving). Far right panels are negative controls for each set. 


\section{DISCUSSION}

Fibroblasts and myofibroblasts are associated with mammary remodeling in other species; therefore, we expected to find an increase in stromal fibroblasts and myofibroblasts during involution and mammogenesis in dairy cows. The number of myofibroblasts did not change during the dry period (cells $/ \mathrm{mm}^{2}$ of intralobular stroma). Although there were no statistical differences detected, there was a trend for myofibroblasts to be greater throughout the dry period compared with late lactation $(P=0.11)$. This increase may be biologically relevant, as myofibroblasts contribute to protein synthesis and have contractile properties that are important to tissue remodeling. We also noted that biopsy stage tended to alter the number of fibroblasts. A decrease in both the number of fibroblasts and in intralobular stromal area was observed as parturition approached. The decline in stromal area may relate to the decrease in fibroblasts, which function to produce stromal proteins. Although we expected that differentiated myofibroblasts would contribute more to the synthesis of stromal proteins than undifferentiated fibroblasts, it is possible that fibroblasts are contributing a greater share of protein abundance in the stroma, and consequently stromal area may depend on the number of fibroblasts. This question would require further testing of the capacity of bovine mammary fibroblasts and myofibroblasts to synthesize stromal proteins at different stages in the dry period.

The greater number of fibroblasts observed at $1 \mathrm{WD}$ may be because of increased abundance of TGF- $\beta 1$ in the intralobular stroma at LL. Musters et al. (2004) demonstrated that exogenous TGF- $\beta 1$ stimulated stromal cell proliferation in prepubertal heifers. Therefore, it is likely that endogenous TGF- $\beta 1$ expressed during LL would contribute to the proliferation of fibroblasts during involution in the dry period of dairy cattle. Our results for TGF- $\beta 1$ expression may seem inconsistent with those of others. For example, Plath et al. (1997) found the abundance of mammary TGF- $\beta 1$ mRNA to be greatest during involution and mammogenesis, whereas Nørgaard et al. (2008) did not find any differences in abundance of TGF- $\beta 1 \mathrm{mRNA}$ in lactation or the dry period of dairy cows. A key difference between these studies may be that Plath et al. (1997) examined involution after induced lactation in virgin heifers, whereas Nørgaard et al. (2008) obtained biopsies during lactation and the dry period of multigravid cows (Plath et al., 1997; Nørgaard et al., 2008). Moreover, neither of these studies examined changes in the abundance of TGF- $\beta 1$ protein in the stromal tissue, nor did their examinations provide a distinction between changes in the stromal tissue and parenchymal tissue.

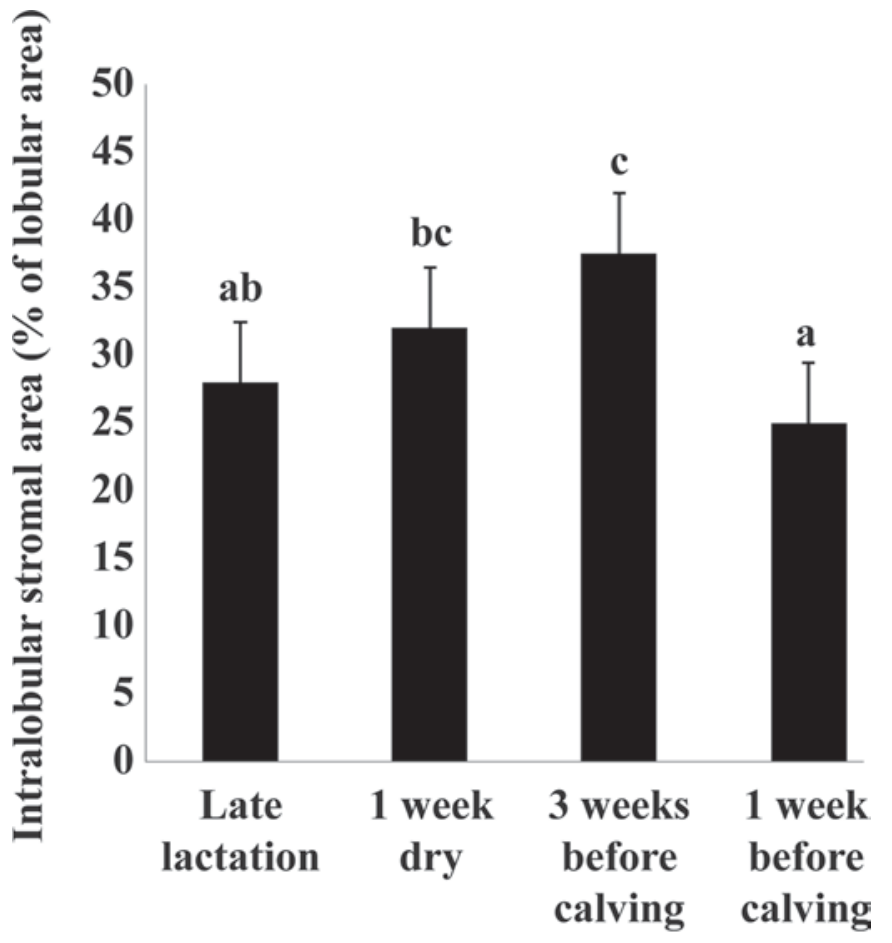

\section{Stage at biopsy}

Figure 3. Intralobular stromal area during late lactation and the dry period. Stromal area was greatest at $3 \mathrm{wk}$ before expected calving and significantly decreased 1 wk before calving $(P=0.02)$. Results are presented as least squares means $\pm \mathrm{SE}$; different letters indicate significant differences at $P=0.05$.

Our results provide new insight into changes in stromal expression of TGF- $\beta 1$. An increase of TGF- $\beta 1$ in the stroma during late lactation may contribute to the decline in milk production in late lactation, as TGF- $\beta 1$ is known to slow epithelial proliferation (Gajewska and Motyl, 2004). Further studies are necessary to test this hypothesis.

Interestingly, the structural integrity of alveoli and their surrounding basement membrane in the LL tissue samples of this study were most heterogeneous of all biopsy stages. In mice, TGF- $\beta$ promoter activity is increased in the absence of a basement membrane and repressed when a functional basement membrane is present (Streuli, 1991). It is possible that the incomplete basement membranes we observed in our LL samples increased the levels of TGF- $\beta$ promoter. Thus, the reduced integrity of the basement membrane at LL in our study may explain, in part, the greater abundance TGF- $\beta 1$ protein expression observed in late lactation. This elevated TGF- $\beta 1$ in the intralobular stroma may, in time, contribute to reduced alveolar function and declining milk production at the end of lactation. 


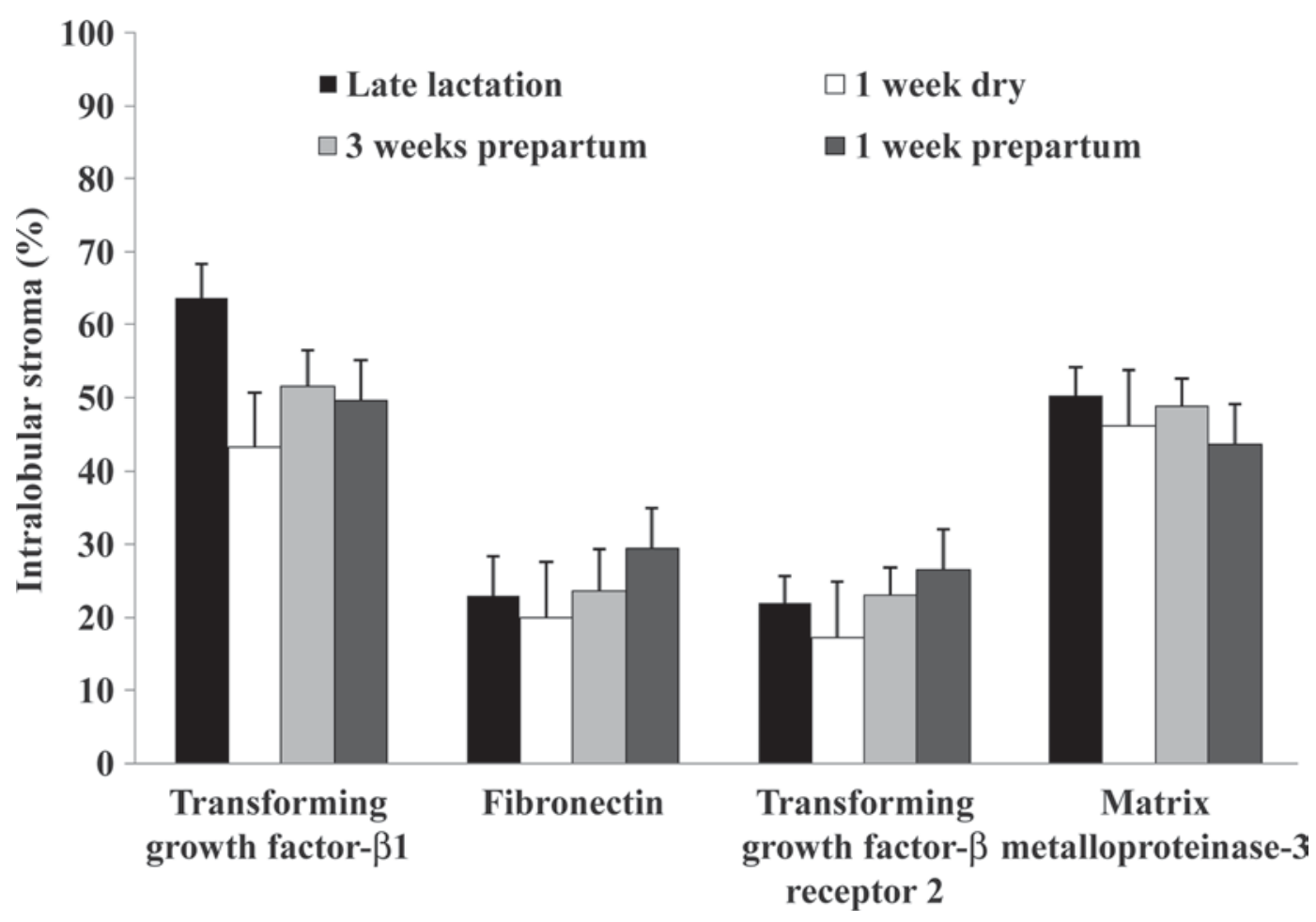

Figure 4. Percentage of intralobular stromal area expressing proteins. Percentage of transforming growth factor- $\beta 1$ in the stromal area decreased from late lactation to the dry period $(P=0.02)$. There was no effect of biopsy stage on staining in the intralobular stroma for matrix metalloproteinase- 3 , fibronectin, or transforming growth factor- $\beta$ receptor 2 . Results are presented as least squares means \pm SE.

It is also interesting to speculate that the greater number of fibroblasts observed at 1 WD may be due to increased abundance of TGF- $\beta 1$ in the intralobular stroma at LL. The TGF- $\beta 1$ protein in late lactation may be in latent form, which is activated by proteases at dry-off (reviewed by Plaut et al., 2003). Activated TGF- $\beta 1$ may then stimulate proliferation of fibroblasts during involution.

The ligand binding receptor in the TGF- $\beta 1$ signal pathway is TGF- $\beta$ R2. Expression of TGF- $\beta$ R2 is necessary to maintain organization of ductal branching during mammary remodeling and development in mice (Joseph et al., 1999). Therefore, we expected an increase in TGF- $\beta$ R2 during the dry period of dairy cows. As with TGF- $\beta 1$, we did not observe the expected increase in abundance of TGF- $\beta$ R2 during the dry period. However, our results for TGF- $\beta$ R2 protein abundance were consistent with those of Nørgaard et al. (2008), who observed no differences in mRNA expression of the receptor during late lactation and the dry period. Although staining intensity was not directly quantified in this study, we observed stronger intensity for TGF- $\beta 1$ and TGF- $\beta$ R2 in the epithelial compartment than in the stromal compartment. Localization of TGF- $\beta$ R2 was consistent with previous literature that reported TGFBR2 staining along the alveolar and ductal epithelium of heifers (Plaut et al., 2003).

Using immunofluorescence, Dickson and Warburton (1992) detected increased protein expression of MMP-3 by myoepithelial cells, in association with degradation

Table 2. Stromal cell changes ${ }^{1}$

\begin{tabular}{|c|c|c|c|c|c|}
\hline Item & \multicolumn{4}{|c|}{ Biopsy stage } & $\mathrm{SE}$ \\
\hline Myofibroblasts (cells $/ \mathrm{mm}^{2}$ ) & 563 & 763 & 618 & 607 & 86 \\
\hline Myofibroblasts (\%) & 18 & 22 & 21 & 22 & 1.8 \\
\hline
\end{tabular}

${ }^{1}$ Values are least squares means. 


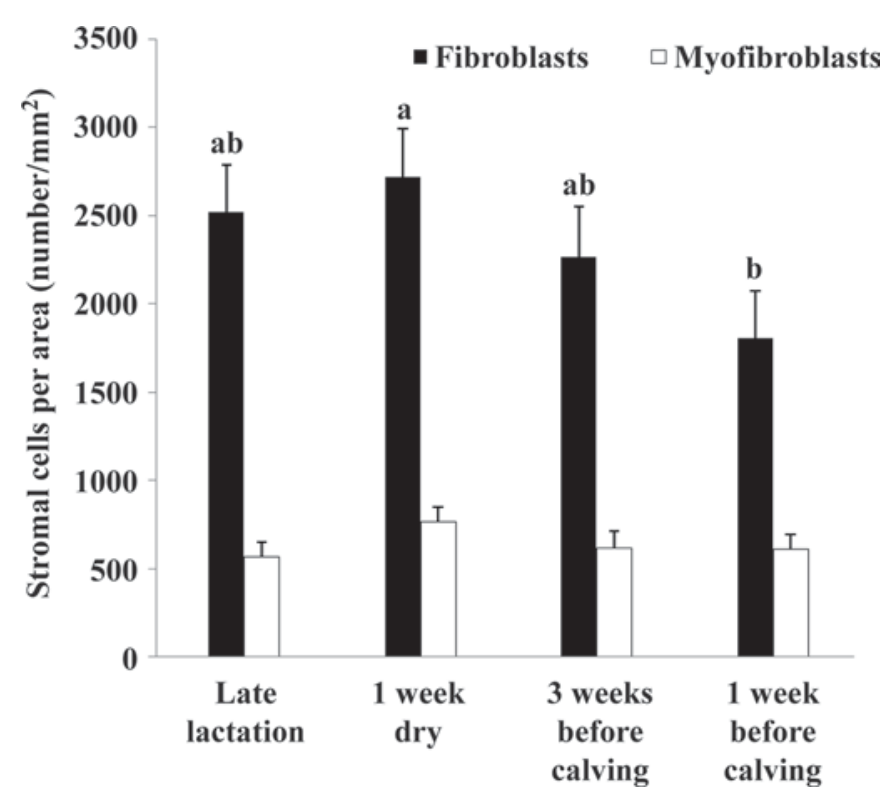

Figure 5. Number of fibroblasts and myofibroblasts expressed as cells per area of intralobular stroma (cells $/ \mathrm{mm}^{2}$ of stroma) at stages of late lactation, 1 wk dry, 3 wk before calving, and 1 wk before calving. The number of fibroblasts decreased from $1 \mathrm{wk}$ dry to $1 \mathrm{wk}$ before calving $(P=0.02)$. The number of myofibroblasts in the stroma was not significantly different. Overall effect of biopsy stage $(P=0.1)$. Results are presented as least squares means \pm SE; different letters indicate significant differences at $P=0.05$.

of the basement membrane during murine mammary involution compared with pregnancy and lactation. The fact that we did not observe an increase in MMP-3 during involution and mammogenesis of the dry period may be consistent with the observation that there is little to no degradation of the basement membrane or detachment of epithelial cells from it in the bovine mammary gland during the dry period, unlike in other species (Capuco and Akers, 1999). Instead, based on our observations, degradation of the basement membrane may be occurring in some regions of the mammary gland in LL in cows. Although we did not quantify the abundance of MMP-3 in the epithelium, histological observations showed more intense staining in the epithelium than in stroma at all biopsy stages. Therefore, MMP-3 produced by the epithelium may contribute to degradation of the basement membrane and thus increase TGF- $\beta 1$ synthesis in late lactation. In addition, the enzymatic activity of MMP-3 in the stroma and epithelium was not measured in this study. Immunohistochemistry would not be sufficient to detect if remodeling during the dry period was mediated by enhanced protease activity, rather than by an increase in protease abundance. This warrants further studies examining MMP-3 abundance in the epithelium and activity in the stroma, particularly during late lactation and involution.
Transforming growth factor- $\beta 1$ induces the differentiation of fibroblasts into myofibroblasts, which have an increased production of the ECM proteins (Petrov et al., 2002). The expression of fibronectin preceded the expression of SMA by human dermal fibroblasts induced to differentiate by TGF- $\beta 1$, indicating that stromal composition mediates this process (Serini et al., 1998). In our study, we expected an increase in intralobular stromal fibronectin concomitant with increases in myofibroblasts during involution and mammogenesis in the dry period. In contrast, the percentage of fibronectin protein expressed in the intralobular stroma was not different across biopsy stages. Although the percentage of fibronectin did not change, the fact that it remained constant as the stromal area changed may be relevant. If the change in stromal area were extrapolated to the entire gland, it would follow that although no differences were detected in percentage area, if the total stromal area was increased, total fibronectin would increase as well. However, this extrapolation would require verifying that the increase in stromal area observed was not merely an effect of dilution because of increased luminal area or an effect of distended ducts compressing the stromal tissue during the onset of lactogenesis.

Capuco et al. (1997) found that hydroxyproline, a marker of collagen synthesis, was greatest during mammogenesis in the dry period of dairy cows, paralleling the time of greatest stromal area. These investigators suggested that this is evidence that changes in stromal area during the dry period are a direct result of an increase in ECM synthesis rather than a change in stromal area by compression or changes in elasticity (Capuco et al., 1997). The fibronectin changes we observed would also support the hypothesis. The increase in intralobular stromal area in the dry period is likely a result of the increased production of stromal proteins, because the percentage of fibronectin in the stroma remained constant across biopsy stages, in spite of changes in intralobular stromal area.

Although repeated biopsies on a single cow over time should reduce animal variability, the use of a single biopsy at each stage may have disadvantages. Akers et al. (1990) reported large variation in the composition of involuting bovine mammary glands. We observed some variation in the LL tissue samples; thus, the tissue obtained may not be representative of the whole gland at this time point. However, with the exception of the late lactation sample, the overall histology at a similar stage was relatively homogeneous between cows in this study. Slaughtering cows for a whole-gland analysis may provide a fuller picture of the gland, but it would likely require more animals because it would not allow a comparison within an animal over time and therefore would not be as cost-efficient as serial biopsies. 


\section{CONCLUSIONS}

The results of this study demonstrate that stromal tissue is dynamic, undergoing changes in composition as it remodels during the dry period. We have shown that intralobular stromal expression of TGF- $\beta 1$ was greater during late lactation than during the dry period and speculate that TGF- $\beta 1$ may be responsible in initiating remodeling as milk production declines toward the end of lactation. In vivo and in vitro studies are needed to test this hypothesis. Transforming growth factor- $\beta 1$ may also be responsible for increasing stromal cell proliferation early in the dry period, as we have shown that the number of fibroblasts in the intralobular stroma is greater at $1 \mathrm{WD}$ than at 1 BEC. Although we did not detect changes in the percentage of the intralobular stroma expressing TGF- $\beta$ R2, MMP-3, or fibronectin, stromal area was greater at 1 WD than at 1 BEC. All of these proteins would have had to increase concomitantly with the stromal area to maintain a constant percentage of the stromal composition, and thus there may have been an overall increase in these proteins and proteases in the gland. Whether it is the total abundance of proteins in the stroma or the percentage stromal composition that is important to remodeling and development remains unanswered. The activity of proteins expressed in the dry period should also be examined to understand mammary remodeling during the dry period. These questions require further investigation to understand bovine-specific mammary changes during the dry period.

\section{ACKNOWLEDGMENTS}

The authors thank the staff at the Michigan State Dairy Teaching and Research Center for their assistance with animal care. This project was supported by National Research Initiative Competitive Grant no. 2006-35206-16719 from the USDA Cooperative State Research, Education, and Extension Service.

\section{REFERENCES}

Akers, R M., W. Beal, T. McFadden, and A. Capuco. 1990. Morphometric analysis of involuting bovine mammary tissue after 21 or 42 days on non-suckling. J. Anim. Sci. 68:3604-3613.

Capuco, A. V., and R. Akers. 1999. Mammary involution in dairy animals. J. Mammary Gland Biol. Neoplasia 4:137-144.

Capuco, A. V., R. Akers, and J. Smith. 1997. Mammary growth in Holstein cows during the dry period: Quantification of nucleic acids and histology. J. Dairy Sci. 80:477-487.

Casey, T. M., T. M. Mulvey, T. A. Patnode, A. Dean, E. Zarzeska, and K. Plaut. 2007. Mammary epithelial cells treated concurrently with TGF- $\alpha$ and TGF- $\beta$ exhibit enhanced proliferation and death. Exp. Biol. 232:1027-1040.

Coppock, C. E., R. W. Everett, R. P. Natzke, and H. R. Ainslie. 1974. Effect of dry period length on Holstein milk production and selected disorders at parturition. J. Dairy Sci. 57:712-718. de Feu, M. A., A. C. O. Evans, P. Lonergan, and S. T. Butler. 2009. The effect of dry period duration and dietary energy density on milk production, bioenergetic status, and postpartum ovarian function in Holstein-Friesian dairy cows. J. Dairy Sci. 92:6011-6022.

Dickson, S. R., and M. Warburton. 1992. Enhanced synthesis of gelatinase and stromelysin by myoepithelial cells during involution of the rat mammary gland. J. Histochem. Cytochem. 40:697703.

Dover, H., M. VandeHaar, J. Liesman, O. Patel, L. De Vries, and K. Plaut. 2008. Serial mammary biopsies in cows do not alter overall milk production. J. Anim. Sci. 86(E. Suppl. 2):441. (Abstr.)

Farr, V. C., K. Stelwagen, L. R. Cate, A. J. Molenaar, T. B. McFadden, and S. R. Davis. 1996. An improved method for the routine biopsy of bovine mammary tissue. J. Dairy Sci. 79:543-549.

Gajewska, M. B., and T. Motyl. 2004. IGF-binding proteins mediate TGF- $\beta 1$-induced apoptosis in bovine mammary epithelial BMEUV1 cells. Comp. Biochem. Physiol. C Toxicol. Pharmacol. 139:65-75.

Greiling, D., and R. A. F. Clark. 1997. Fibronectin provides a conduit for fibroblast transmigration from collagenous stroma into fibrin clot provisional matrix. J. Cell Sci. 110:861-870.

Hurley, W. L. 1989. Mammary gland function during involution. J. Dairy Sci. 72:1637-1646.

Jiao, Y., Z. Sun, T. Lee, F. Fusco, T. Kimble, C. Meade, S. Cuthbertson, and A. Reiner. 1999. A simple and sensitive antigen retrieval method for free-floating and slide-mounted tissue sections. J. Neurosci. Methods 93:149-162.

Joseph, H., A. E. Gorska, P. Sohn, H. L. Moses, and R. Serra. 1999. Overexpression of a kinase-deficient transforming growth factorbeta type II receptor in mouse mammary stroma results in increased epithelial branching. Mol. Biol. Cell 10:1221-1234.

Klein, J. W., and T. E. Woodward. 1943. Influence of length of dry period upon the quantity of milk produced in the subsequent lactation. J. Dairy Sci. 26:705-713.

Knight, C., and M. Peaker. 1984. Mammary development and regression during lactation in goats in relation to milk secretion. Exp. Physiol. 69:331-338.

Kratochwil, K. 1969. Organ specificity in mesenchymal induction demonstrated in the embryonic development of the mammary gland of the mouse. Dev. Biol. 20:46-71.

Kuhn, M. T., J. L. Hutchison, and H. D. Norman. 2006. Dry period length to maximize production across adjacent lactations and lifetime production. J. Dairy Sci. 89:1713-1722.

Levine, J. F., and F. E. Stockdale. 1985. Cell-cell interactions promote mammary epithelial cell differentiation. J. Cell Biol. 100:14151422.

Musters, S., K. Coughlan, T. McFadden, R. Maple, T. Mulvey, and K. Plaut. 2004. Exogenous TGF-beta1 promotes stromal development in the heifer mammary gland. J. Dairy Sci. 87:896-904.

Nørgaard, J., P. Theil, M. Sorensen, and K. Sejrsen. 2008. Cellular mechanisms in regulating mammary cell turnover during lactation and dry period in dairy cows. J. Dairy Sci. 91:2319-2327.

Petrov, V. V., R. H. Fagard, and P. J. Lijnen. 2002. Stimulation of collagen production by transforming growth factor- $\beta 1$ during differentiation of cardiac fibroblasts to myofibroblasts. Hypertension 39:258-263.

Phan, S. H. 2008. Biology of fibroblasts and myofibroblasts. Proc. Am. Thorac. Soc. 5:334-337.

Plath, A., R. Einspanier, F. Peters, F. Sinowatz, and D. Schams. 1997. Expression of transforming growth factors alpha and beta-1 messenger RNA in the bovine mammary gland during different stages of development and lactation. J. Endocrinol. 155:501511.

Plaut, K., A. J. Dean, T. A. Patnode, and T. M. Casey. 2003. Effect of transforming growth factor-beta (TGF- $\beta$ ) on mammary development. J. Dairy Sci. 86(E Suppl.):E16-E27.

Rabot, A., F. Sinowatz, B. Berisha, H. H. D. Meyer, and D. Schams 2007. Expression and localization of extracellular matrix-degrading proteinases and their inhibitors in the bovine mammary gland during development, function, and involution. J. Dairy Sci 90:740-748. 
Roberts, A. B., B. M. B. Sporn, R. K. Assoian, J. M. Smith, N. S. Roche, L. M. Wakefield, U. I. Heine, L. A. Liotta, V. Falanga, and J. H. Kehrl. 1986. Transforming growth factor type beta: Rapid induction of fibrosis and angiogenesis in vivo and stimulation of collagen formation in vitro. Proc. Natl. Acad. Sci. USA 83:41674171.

Serini, G., M. Bochaton-Piallat, P. Ropraz, A. Geinoz, L. Borsi, L. Zardi, and G. Gabbiani. 1998. The fibronectin domain ED-A is crucial for myofibroblastic phenotype induction by transforming growth factor- $\beta 1$. J. Cell Biol. 142:873-881.

Silberstein, G. B., K. C. Flanders, A. B. Roberts, and C. W. Daniel. 1992. Regulation of mammary morphogenesis: Evidence for extracellular matrix-mediated inhibition of ductal budding by transforming growth factor-beta1. Dev. Biol. 152:354-362.

Simian, M., Y. Hirai, M. Navre, Z. Werb, A. Lochter, and M. Bissell. 2001. The interplay of matrix metalloproteinases, morphogens and growth factors is necessary for branching of mammary epithelial cells. Development 128:3117-3131.

Sordillo, L. M., and S. C. Nickerson. 1988. Morphologic changes in the bovine mammary gland during involution and lactogenesis. Am. J. Vet. Res. 49:1112-1120.

Sorrell, D. A., M. Szymanowska, M. Boutinaud, C. Robinson, R. W. Clarkson, T. Stein, D. J. Flint, and A. F. Kolb. 2005. Regulation of genes encoding proteolytic enzymes during mammary gland development. J. Dairy Res. 72:433-441.

Streuli, C H. 1991. Control of mammary epithelial differentiation: basement membrane induces tissue-specific gene expression in the absence of cell-cell interaction and morphological polarity. J. Cell Biol. 115:1383-1395.

Swanson, E. W. 1965. Comparing continuous milking with sixty-day dry periods in successive lactations. J. Dairy Sci. 48:1205-1209.

Sympson, C. J., R. Talhouk, C. Alexander, J. Chin, S. Clift, M. Bissell, and Z. Werb. 1994. Targeted expression of stromelysin-1 in mammary gland provides evidence for a role of proteinases in branching morphogenesis and the requirement for an intact basement membrane for tissue-specific gene expression. J. Cell Biol. 125:681-693.

Talhouk, R. S., M. Bissell, and Z. Werb. 1992. Coordinated expression of extracellular matrix-degrading proteinases and their inhibitors regulates mammary epithelial function during involution. J. Cell Biol. 118:1271-1282

Watters, R. D., M. C. Wiltbank, J. N. Guenther, A. E. Brickner, R. R. Rastani, P. M. Fricke, and R. R. Grummer. 2009. Effect of dry period length on reproduction during the subsequent lactation. J. Dairy Sci. 92:3081-3090.

Wilde, C. J., C. Addey, P. Li, and D. Fernig. 1997. Programmed cell death in bovine mammary tissue during lactation and involution. Exp. Physiol. 82:943-953.

Yao, H. W., Q. Xie, J. Chen, Y. Deng, and H. Tang. 2004. TGF-31 induces alveolar epithelial to mesenchymal transition in vitro. Life Sci. $76: 29-37$. 